\title{
nature
}

\section{Strength in unity}

\section{Adapting to reunification has been a painful process for much of the scientific community in the former East}

Germany. But the city of Magdeburg has shown how a successful outcome can be achieved.

$\mathrm{t}$ is a truism that upbringing influences character. Nowhere is this more clearly demonstrated than in the research institutes in the former German Democratic Republic, where, in the period since reunification, west and east German scientists have been thrown together, often uncomfortably. During the restructuring of research organizations along western lines, for example, many senior east German academics lost their jobs to west Germans when most academic posts were opened to competition. Some were deemed unemployable because of their political past. Others were simply not felt to be at the cutting edge of research.

Five years after completion of this unique exercise in social engineering, however, some of the rewards are now emerging. Magdeburg is a shining example (see page 725). The quality of research now being undertaken, particularly in the neurosciences, is as high as anywhere in west Germany. East German scientists who kept their posts say their work in more interesting and fulfilling than before; west Germans appreciate the opportunity to build something new and significant, particularly at a time when support for research has contracted in the west. So good is the current situation that one senior researcher last year turned down a prestigious chair in Bonn to continue his research in Magdeburg.

But the undercurrents created by a strong and continuing east-west culture clash tell a different story. West German scientists are frustrated by the tendency towards a bureaucratic and cautious approach to problems of east Germans, brought up in a society where it was unwise to have strong opinions, or to make decisions without the support of one's superiors. Appeals to eastern researchers from western colleagues to use their initiative are still sometimes seen by the former as potential traps.

East German scientists continue to resent what they feel to be colonization by westerners who tend to dismiss their entire pre-reunification lives as having little value, and western values that have ruined the careers of many former colleagues. They often view their new west German bosses as arrogant and aggressive in their demand for constant progress, and see an enforced continual competition for jobs and research money as unnecessarily stressful.

In practice, the two sides usually manage to work well together, largely because, whatever the underlying tensions, it is easier, more fun and more satisfying for a researcher from the east to work in a well-equipped modern laboratory, with much greater personal freedom than before. But, understandably, experienced researchers seldom choose to mix socially.

It is therefore reassuring to see how, only eight years after reunification, young scientists already appear free of the same tensions. Those who were still undergraduates in 1990 have been brought up under a single system of research training, and, moreover, appear able to enjoy one another's company both during and after working hours unburdened by recent history. This, together with the high calibre of the research staff appointed from the west - by no means the case in all parts of east Germany — has been an essential element in the success of Magdeburg in establishing itself as a centre of research excellence. It is also a hopeful sign for the future of German science.

\section{Science advice in an uncertain world}

\section{Despite pressures to the contrary, debate on the scientific dimension of policy decisions must take place openly.}

ast week, a large agricultural products company whose trial plots of genetically modified crops had been attacked by protesters came up with a simple proposal: that in future, the precise location of experimental crops should be kept secret. The suggestion has obvious attractions. But it would also be a dangerous and misguided move. For nothing generates distrust of science and technology more than excessive secrecy, and the feeling that, if something is being kept out of the public eye, it must be potentially embarrassing - if not dangerous.

The same need for openness applies to science advice to governments. In an earlier era, science could count on public trust, and such advice could be drawn up as a matter of course by expert committees and submitted to decision-makers on a confidential basis. But today - a lesson learnt in the United States through the Watergate affair, and more recently in Britain by the BSE crisis confidence in political decisions requires confidence in the political process. And this requires responsiveness to the electorate's demand for transparency.

The BSE crisis weighed heavily on the mind of Sir Robert May, Britain's chief scientific adviser, when he made an eloquent plea last week in defence of openness (see page 720). According to Sir Robert, this process should extend to the debates between scientific experts. If respected advisers were encouraged to air their differences in public, he argued, everyone would get a better idea of how scientific knowledge is built up, not by maximizing certainty or striving awkwardly for consensus, but by minimizing uncertainty.

A different but equally radical proposal comes in a submission to the same inquiry from the Royal Society. This is the notion that the chief scientist should have access not only to the principal science advisers in all government departments, but also to debates on scientific issues taking place within those departments; again, BSE provides a demonstration of what can happen when such access is denied.

All such proposals, of course, will meet counter-arguments. Those concerning commercial confidentiality or national security are often (though not always) valid. Others, such as the tradition that policy-related questions require the type of clear, unambiguous answer that science is often unable to provide, can be less so. There will always be those who exploit openness for their own ends, as those responsible for destroying the experimental crops seem determined to do. And there are times when a clear statement of scientific consensus is essential. But the ability to handle openly the type of uncertainty that scientific knowledge can lead to is itself a form of social maturity. 